\title{
Results of surgical repair for dissection of the ascending aorta
}

\author{
A J MURDAY, R PILlAi, P G MAGEE, R K WALESBY, J E C WRIGHT, \\ M F STURRIDGE
}

From the London Chest Hospital

SUMMARY Between 1970 and 1986, 40 patients had surgical treatment for dissection of the ascending aorta at the London Chest Hospital. The overall hospital mortality was $27 \cdot 5 \%$. Preoperative renal impairment and age $\geqslant 60$ years were both associated with a significantly increased hospital mortality. In the long term one patient was lost to follow up. There have been two late deaths among the remaining 28 patients (mean follow up 4.4 years). The functional state of the survivors is good, with only three having any cardiac disability.

Aortic dissection was first described by Sennertus in 1628. ${ }^{1}$ In 1769 Morgagni deduced that the condition arose as a result of blood forcing its way through the layers of the aortic wall. ${ }^{2}$ The earliest attempts at surgical repair were unsuccessful, ${ }^{34}$ until 1955, when DeBakey et al described an operation in which the false lumen was obliterated and aortic continuity restored by means of a graft. ${ }^{5}$ This, together with measures to combat complications of the condition such as aortic incompetence and major vessel occlusion, remains the rationale behind the surgical management of aortic dissection.

We have analysed the early and late results of surgical repair for dissection of the ascending aorta at the London Chest Hospital from 1970 up to February 1986. There is still debate about the ideal treatment for dissection of the descending aorta. ${ }^{6}$ It is our policy to use medical management for dissections confined to the descending aorta.

The classification developed by DeBakey and his coworkers ${ }^{7}$ defines type I dissections as those which affect the ascending and descending aorta, type II dissections as affecting only the ascending aorta, and type III dissections as starting distal to the origin of the left subclavian artery and not extending retrogradely. Miller et al group dissections of types I and II together as type A and they call type III dissections type $B{ }^{6}$ In this report we have adopted the classification of Miller et al.

Requests for reprints to Dr A J Murday, The London Chest Hospital, Bonner Road, London E2 9JX.

Accepted for publication 19 February 1987

\section{Patients and methods}

We analysed the case notes of all patients who had undergone surgery for aortic dissection since 1970, noting the details of preoperative history, clinical state, and laboratory results. We also examined operation records to determine the nature of the operative intervention, noting postoperative complications. Hospital survivors were traced. Those still alive were contacted by telephone and asked a series of questions about their current state of health. The cause of death in patients who died after operation was obtained from the records of their family practitioners and, where relevant, from the records of other hospitals.

Fisher's exact probability test was used to determine whether or not various preoperative factors had any statistically significant effect upon hospital mortality.

\section{Results}

\section{PATIENTS}

Forty patients (29 M, $11 \mathrm{~F})$, aged $17-74$ (mean 55 ), had surgical treatment for dissection of the ascending aorta.

\section{AETIOLOGY}

Hypertension was the most common aetiological factor. Fifteen $(38 \%)$ patients had hypertension before operation. Two $(5 \%)$ cases were the direct result of cardiac catheterisation. Two patients had clear stigmata of Marfan's syndrome, and one case occurred 10 days after aortic valve replacement. The 
Table l Operative procedures

\begin{tabular}{lc}
\hline Operation & No \\
\hline Aortic graft alone & $17^{\star}$ \\
Aortic repair alone & $7^{\star}$ \\
Aortic graft with valve repair & 9 \\
Aortic graft with valve replacement & 2 \\
Aortic repair with valve repair & 1 \\
Aortic repair with valve replacement & 3 \\
No procedure & 1 \\
\hline *In each of these categories one patient had concurrent coronary \\
artery surgery.
\end{tabular}

largest group, consisting of $19(48 \%)$ patients, had no obvious aetiological factors.

\section{DIAGNOSIS}

In most patients dissection was diagnosed by aortography (34/40), while two cases were undiagnosed preoperatively and one was diagnosed by plain chest $x$ ray. Recently we have been assessing the role of digital subtraction aortography after intravenous injection of contrast; three patients had the repair operation after this investigation alone.

\section{ANATOMICAL TYPE}

Of the $\mathbf{4 0}$ patients with type $A$ dissections that make up this series, 25 were operated upon within two weeks of the onset of symptoms (acute) and 15 beyond two weeks (chronic).

\section{PREOPERATIVE PROCEDURE}

Table 1 summarises the operative procedures. Before 1978 coronary perfusion was used and thereafter cardioplegic arrest. One of the $\mathbf{4 0}$ patients died before cardiopulmonary bypass could be established. Two patients underwent concurrent coronary artery bypass grafting.

\section{HOSPITAL MORTALITY}

There were 11 hospital deaths; thus the overall hospital survival rate was $72.5 \%$. Table 2 gives the causes of death. In the single case in which it proved impossible to establish cardiopulmonary bypass all the femoral perfusion entered the false lumen, compressing and occluding the branches of the aortic arch; the patient died.

\section{Table 2 Causes of hospital mortality}

\begin{tabular}{ll}
\hline Cause & No \\
\hline Haemorrhage & 4 \\
Cardiorespiratory failure & 3 \\
Cerebral embolus & 1 \\
Intestinal infarction & 1 \\
Renal failure & 1 \\
Unable to establish bypass & 1 \\
\hline
\end{tabular}

Table 3 Hospital mortality related to preoperative complications and other factors

\begin{tabular}{ll}
\hline & Hospital mortality \\
\hline Age: & \\
$<60$ yr & $4 / 28(14 \%)$ \\
$\geqslant 60$ yr & $7 / 12(58 \%)$ \\
Renal impairment: & $6 / 9(67 \%)$ \\
Present & $5 / 31(16 \%)$ \\
Absent & $5 / 10(50 \%)$ \\
Year of operation: & $6 / 30(20 \%)$ \\
Up to 1977 & $5 / 12(42 \%)$ \\
After 1977 & $6 / 28(21 \%)$ \\
Haemopericardium: & $6 / 26(23 \%)$ \\
Present & $5 / 14(36 \%)$ \\
Absent & \\
Aortic incompetence: & \\
Present & \\
Absent & \\
\hline
\end{tabular}

\section{RISK FACTORS}

The relation of several preoperative indices to hospital mortality was examined to identify factors that affected operative risk (table 3 ).

(a) year of operation-Between 1970 and 1977, 10 patients underwent surgical repair for aortic dissection. Over this period hospital mortality was $50 \%$. Between 1978 and 198630 patients had surgical repair and six $(20 \%)$ died in hospital after the operation. This difference does not quite reach statistical significance $(p=0.08)$ (Fisher's exact test).

(b) Renal impairment-Nine patients had renal impairment (raised plasma urea or creatinine or urine output $<20 \mathrm{ml} /$ hour) before operation. In this group hospital mortality was $6 / 9(67 \%)$ compared with $5 / 31(16 \%)$ in those patients without renal impairment. This difference is statistically significant by Fisher's exact probability test $(p<$ 0.05).

(c) Age-Twelve of the 40 patients were $\geqslant 60$ years at operation. The mortality for this group was $7 / 12(58 \%)$ compared with $4 / 28(14 \%)$ for patients who were $<60$ at operation. This difference just reaches statistical significance (Fisher's test, $\mathrm{p}=$ 0.05).

(d) Haemopericardium was present at operation in 12 patients; however, this finding had no statistically significant effect upon hospital mortality. Five patients with haemopericardium died, compared with six of the 28 without haemopericardium.

(e) Aortic valve regurgitation-There was evidence of aortic regurgitation in 26 patients before operation and six $(23 \%)$ of these patients died within 30 days of operation. Five $(36 \%)$ of the 14 patients without evidence of aortic incompetence died. This difference is not statistically significant.

(f) Sex-The hospital mortality for male patients was $7 / 28(25 \%)$ and that for female patients was $4 / 12$ $(33 \%)$. This difference is not statistically significant. 


\section{EARLY NON-FATAL COMPLICATIONS}

Five serious non-fatal complications occurred within the early postoperative period. One patient suffered paraplegia which did not resolve. Hemiplegia developed in another patient, who made a complete recovery. There was a single episode of retinal infarct, resulting in a partial field defect in one eye, that did not resolve. Endocarditis caused by Staphylococcus aureus developed in one patient. This was successfully treated with antibiotics. The fifth patient developed acute renal failure after septicaemia, which was successfully treated without long term sequelae.

\section{LONG TERM FOLLOW UP}

One patient was lost to follow up immediately after hospital discharge. All the other 28 hospital survivors have been followed up to the present time. The average time from operation to the present is 4.4 years. There have been two late deaths. One patient with Marfan's disease died two years after his original operation (aortic repair) having undergone two subsequent aortic root replacements. The other died from heart failure five years after operation (aortic valve replacement and aortic repair). Three further patients suffered events that may be related to the original aortic dissection. One patient developed aortic regurgitation requiring aortic valve replacement four years after valve resuspension and ascending aorta repair for an acute dissection. This patient is well 2.5 years later. One patient had an abdominal aortic aneurysm repaired three years after repair of a chronic dissection. A third patient suffered a right hemiplegia two years after ascending aortic replacement with a Dacron graft for a chronic dissection. Of the 26 known long term survivors, 23 are symptom free and in the other three activity is slightly restricted by cardiovascular disability. Twelve patients are in full time employment.

\section{Discussion}

Hospital mortality associated with surgical treatment of type A aortic dissection is high, but that associated with medically treated patients is higher. ${ }^{8}$ Opinion is divided on the relative merits of surgical and medical treatment of type B aortic dissection. Whereas DeBakey and his collegues in Houston advocate surgical treatment for these patients, ${ }^{7}$ there is considerable evidence that elsewhere the results of medical management are just as good. ${ }^{910}$ This is why at the London Chest Hospital patients with aortic dissections of the ascending aorta (type A) are treated surgically, and those with dissections that are restricted to the descending aorta (type B) are treated medically.
Murday, Pillai, Magee, Walesby, Wright, Sturridge

Like others, ${ }^{11} 12$ we found a history of systemic hypertension in most patients presenting with aortic dissection. The only other notable aetiological factors were Marfan's disease and trauma at either angiography or cardiac surgery.

The preferred method of preoperative diagnosis will always depend upon the facilities available within the unit. Direct aortography has become the established method, but computerised tomography, ${ }^{13}$ magnetic resonance, ${ }^{14}$ and digital subtraction aortography after intravenous injection of contrast $^{15}$ are alternatives. Recently, we have been using digital subtraction aortography as a first line method of diagnosis at the London Chest Hospital. So far three patients have had a repair operation after this investigation alone.

What information does the surgeon require to treat an aortic dissection? Confirmation of diagnosis is essential. Whether the site of the intimal tear must be known is open to question. The site of the tear is irrelevant if the only object of the operation is to restore the integrity of the lumen of the ascending aorta and the aortic valve. Many surgeons argue that coronary angiography is required so that incidental coronary artery disease may be recognised and treated. There is no evidence available upon which to base a rational decision about the merits of bypass grafting for these incidental lesions. We find that diagnosis established by digital subtraction angiography after intravenous injection of contrast is sufficient in most cases.

The surgical procedures used vary with time and between different surgeons. The principles of the surgical intervention, however, remain constant. These are restoration of the integrity of the ascending aortic wall by oversewing the two layers with or without an interposition graft and reestablishment of aortic competence when necessary, either by aortic valve replacement or by resuspension of the aortic valve when possible.

In common with other reports, ${ }^{1617}$ several preoperative factors were found to affect outcome significantly. Patients aged $\geqslant 60$ had over three times the hospital mortality of those aged $<60$. Preoperative renal impairment also trebled the hospital mortality. Perhaps not surprisingly, hospital mortality has fallen progressively with time; however, the difference between the two periods (1970-1977 and 1978-1986) does not reach statistical significance. Neither the presence of haemopericardium or regurgitation at the aortic valve affected surgical outcome.

For hospital survivors $(72.5 \%$ of those who underwent surgery) the prospects of a return to full activity were good. Only one patient was lost to follow up. Two patients have died, both from 
cardiovascular causes. But the vast majority of the long term survivors (23 out of 26 ) reported that their activity was not restricted by cardiovascular disability; and 12 patients were in full time employment. Since the average age of all the patients at the time of operation was 55 years, a large proportion of those not in full time employment are now beyond retirement age.

\section{References}

1 Shennan T. Dissecting aneurysms. (Medical Research Council Special Report Series No 193.) London: HMSO, 1934.

2 Morgagni JB. The seats and causes of diseases investigated by anatomy, vol 1. (Alexander B, translator) London: A Miller, T Cadele, 1769:808-9.

3 Paullin JE, James DF. Dissecting aneurysms of the aorta. Postgrad Med 1948;4:291-9.

4 Johns TNP. Dissecting aneurysm of the abdominal aorta. Report of a case with repair by perforation. Ann Surg 1953;137:232-5.

5 DeBakey ME, Cooley DA, Creech O Jr. Surgical considerations of dissecting aneurysm of the aorta. Ann Surg 1955;142:586-612.

6 Miller DG, Stinson EB, Oyer PE, et al. Operative treatment of aortic dissections. $J$ Thorac Cardiovasc Surg 1979;78:365-82.

7 DeBakey ME, McCollum $\mathrm{CH}$, Crawford S, et al. Dissection and dissecting aneurysms of the aorta. Twenty year follow-up of five hundred twenty-seven patients treated surgically. Surgery 1982;92:1118-34.
8 Wheat MW, Harris PD, Malm JR, Kaiser G, Bowman FO, Palmer RF. Acute dissecting aneurysms of the aorta. Treatment and results in 64 patients. $J$ Thorac Cardiovasc Surg 1969;58:344-51.

9 Anagnostopoulos CE. Medical therapy of acute aortic dissection. Introduction. In: Anagnostopoulos $\mathrm{CE}$, Athanasuleas CL, Garrick TR, Palissian RB, eds. Acute aortic dissections. Baltimore: University Park Press, 1975:209-11.

10 Dorghazi RM, Slater EE, DeSanctis RW. Medical therapy of aortic dissection. Cardiovasc Med 1981;6: 187-98.

11 Wilson SK, Hutchins GM. Acute dissecting aneurysms. Causative factors in 204 subjects. Arch Pathol Lab Med 1982;106:175-80.

12 Larson EW, Edwards WD. Risk factors for aortic dissection: a necropsy study of 161 cases. Am J Cardiol 1984;53:849-55.

13 Moncada R, Churchill R, Reynes C. Diagnosis of dissecting aortic aneurysm by computed tomography. Lancet 1981;i:238-41.

14 Amparo EG, Higgins CB, Hricak H, Sollitto R. Aortic dissection: magnetic resonance imaging. Radiology 1985;155:399-406.

15 Guthaner DF, Miller DC. Digital subtraction angiography of aortic dissection. American Journal of Roentgenology 1983;141:157-61.

16 Miller DC, Mitchell RS, Oyer PE, Stinson EB, Jamieson SW, Shumway NE. Independent determinants of operative mortality for patients with aortic dissection. Circulation 1984;70(suppl I): I-153-64.

17 Doroghazi RM, Slater EE, DeSanctis RW, Buckley MJ, Austen WG, Rosenthal S. Long-term survival of patients with treated aortic dissection. J Am Coll Cardiol 1984;3:1026-34. 